\title{
Correction: p53 and metabolism: from mechanism to therapeutics
}

\author{
Fernando M. Simabuco ${ }^{1}$, Mirian G. Morale ${ }^{2,3}$, Isadora C. B. Pavan ${ }^{1}$, Ana P. Morelli ${ }^{1}$, \\ Fernando R. Silva ${ }^{1}$ and Rodrigo E. Tamura ${ }^{4}$ \\ ${ }^{1}$ Laboratory of Functional Properties in Foods, School of Applied Sciences (FCA), Universidade de Campinas (UNICAMP), \\ Limeira, São Paulo, Brazil \\ ${ }^{2}$ Center for Translational Investigation in Oncology/LIM24, Instituto do Câncer do Estado de São Paulo (ICESP), São Paulo, \\ Brazil \\ ${ }^{3}$ Department of Radiology and Oncology, Faculdade de Medicina, Universidade de São Paulo, São Paulo, Brazil \\ ${ }^{4}$ Universidade Federal de São Paulo, Departamento de Ciências Biólogicas, Diadema, SP, Brazil \\ Published: September 21, 2018
}

Copyright: Simabuco et al. This is an open-access article distributed under the terms of the Creative Commons Attribution License 3.0 (CC BY 3.0), which permits unrestricted use, distribution, and reproduction in any medium, provided the original author and source are credited.

This article has been corrected: The correct author affiliation is given below:

\section{Rodrigo E. Tamura ${ }^{4}$}

${ }^{4}$ Universidade Federal de São Paulo, Departamento de Ciências Biólogicas, Diadema, SP, Brazil

Original article: Oncotarget. 2018; 9:23780-23823. https://doi.org/10.18632/oncotarget.25267 